B I O S C I E N C E

J O U R N A L

\section{ASSESSMENT OF GENETIC DIVERSITY IN CHINESE HULLESS BARLEY ACCESSIONS FOR QUALITATIVE TRAITS}

\footnotetext{
${ }^{1}$ Department of Plant Genetics and Breeding, College of Agronomy, Sichuan Agricultural University, Wenjiang district Chengdu city, Sichuan province, China

2 Department of crop cultivation, College of Agronomy, Sichuan Agricultural University, Wenjiang district Chengdu city, Sichuan province, China.

3 Program of Seed Science and Engineering, Sichuan Agricultural University, Wenjiang district Chengdu city, Sichuan province, China.

${ }^{4}$ Department of Plant Breeding and Genetics, Sindh Agriculture University, Tandojam, Pakistan.

5 Department of Plant Protection, Sindh Agriculture University, Tandojam, Pakistan.
}

Corresponding author:

Zongyun Feng

Email: zyfeng49@126.com

How to cite: MEMON, S., et al. Assessment of genetic diversity in Chinese hulless barley accessions for qualitative traits. Bioscience Journal. 2021, 37, e37046. https://doi.org/10.14393/BJ-v37n0a2021-53703

\begin{abstract}
Cultivated barley (Hordeum vulgare L.) has been proven to be an economically important model plant and having large genetic diversity among the species. The effective exploitation of qualitative characters in barley can be measured by its genetic diversity and interrelationship. This study aims to determine the assessment of genetic diversity in Chinese hulless barley accessions for qualitative traits. Presently, in this study, the genetic diversity of 208 Chinese hulless barley from different Provinces of China, 111 genotypes were from the Tibet plateau, 30 Sichuan, 2 USA, 1 Canada, 12 Gansu, 51 Qinghai, 1 Yunnan was investigated; collected. Almost all the qualitative traits including crude protein, fiber, starch, neutral detergent fiber, and acid detergent fiber exhibited significantly high variability $(p \leq 0.0001)$ among the cultivars. The data were analyzed using Statistics 8.1. In this study, significantly high variation was observed between starch content and neutral detergent fiber (23.64\% and $11.54 \%$ ). However, the highest diversity is based on the magnitude of the coefficient of variation exhibited in crude protein (13.82\%), starch (12.87\%), and fiber (12.17\%). There was a significantly positive correlation between fiber, acid detergent fiber, and neutral detergent fiber except for starch content with crude protein and fiber that exhibited a significant negative correlation ( $r=-$ $0.38^{* * *}$ and $r=-0.92^{* * *}$ ). A large genetic diversity was observed through cluster analysis among all the 208 barley accessions, distance coefficient ranging between 0.28 and 75.86 . The histogram revealed that frequency distributions of 208 different genotypes of hulless barley crop with all five different characters, crude protein, fiber, starch, neutral detergent fiber, and acid detergent fiber, showed normal distribution. It is concluded that this hulless barley study showed genetic diversity among the accessions and confirmed genetic diversity in various traits used.
\end{abstract}

Keywords: Barley. Chinese Hulless Barley. Cluster Analysis. Genetic Diversity. Qualitative Traits. 


\section{Introduction}

The hulless barley (Hordeum vulgare L. var. nudum) has been domesticated as a main staple food crop for Tibetans since ancient times, where it was locally called as "Qingke in Chinese and "Ne" in Tibetan language ( Zeng et al., 2015; Elakhdar et al., 2018). Its importance lies in the Tibetan Plateau as a feed for livestock and in the form of grain used for malting and brewing for the manufacture of beer and whisky (Youssef et al. 2013). Both hulled and hulless barley have always considered a great nutritional value, rich in antioxidants and having a low glycemic index, which reduces the risk of chronic diseases. Though hulless barley contains more crude protein and less crude fiber than hulled barley, but considering the significance of $\beta$-glucans present in the hulless barley, provides easy milling in the form of whole-grain flour and have greater water absorption capacity ( Narwal et al. 2017; Kumar et al. 2018).

Hulless barley has been domestically distributed towards East Asia, Nepal, Bhutan, Korea, Japan, and Tibet of China. However, in China, the overall collection of hulless barley accounts for $77 \%$ of the world's genetic resources (Guo et al. 2012). Hulless barley is mainly distributed in the Qinghai-Tibet Plateau, covering Tibet, Qinghai, Gansu, Sichuan, and Yunnan Provinces of China. Hulless barley is mainly distributed in the Qinghai-Tibet Plateau, covering Tibet, Qinghai, Gansu, Sichuan, and Yunnan Provinces of China. Since, about 3500 years ago, the hulless barley has been planted on the Qinghai-Tibet plateau, inspiring the spiritual culture of barley crop and illuminating the natural features of barley with rich nutrients on the Qinghai-Tibet Plateau (Zeng et al. 2015). Due to its unique importance of geographical location and climatic diversity, abundant landrace of hulless barley is grown in this area (Guo et al. 2012; Liu et al., 2019). The evidence of molecular studies have declared that Tibetan hulless barley may have been domesticated under distinct processes of natural selection compared with the cultivated barley and they have adapted to the harsh environments of the plateau (Liu et al. 2019). Globally, 75\% of the barley is normally used for animal feed, $20 \%$ is used for alcoholic and non-alcoholic beverages, and 5\% in different products (Ferreira et al. 2016). The grain of barley consists of low fat, starch, protein, insoluble and soluble fiber with specific health benefits (Baik 2014; Kumar et al. 2018). Moreover, for health benefits, different phytochemicals, and compounds such as sterols, tocopherols, tocotrienols, phenolic, and antioxidants are present in hulless barley grains (Bleidere et al. 2017). Starch is the major component of hulless barley contributing $70 \%$ of the dry weight. It is a by-product of the fractionation industry (Zhu 2017); therefore, it is considered that the quality of hulless barley-based food products is highly affected by the starch properties.

The hulless barley has been profoundly found to be a short cell life, self-pollinating plant prevailing great genetic variation in cultivated and wild species leading to the ease of hybridization techniques to produce potential genotypes of barley and become a model experimental system (Matsumoto et al. 2011; Kumar et al. 2014). Moreover, protein and starch contents are the major quality traits for barley breeding as both provide a nutritional and commercial value (Gous et al. 2015; Kaur et al. 2016). Protein in barley constitutes $8-27 \%$ of the total grain weight and fulfills storage, structural and metabolic functions for commercial purposes. While carbohydrates are present approximately $80 \%$ of the total dry grain weight and contain starch, sugars, and non-starch polysaccharides (Gous et al. 2015).

Genetic diversity in hulless barley provides opportunities to identify new hulless barley accessions for different uses (Bleidere et al. 2017). This study of genetic diversity elucidates the variation among various groups or individuals or populations and is analyzed by a specific method or with the combination of different methods (Eshghi and Akhundova 2010). The assessment of genetic diversity with different techniques could provide and complementary information for improvement in breeding programs. Criteria for the estimation of genetic diversity can be different such as pedigree records, morphological traits, biochemical markers and molecular markers (Elakhdar et al. 2018). However, the vast knowledge of genetic diversity and potential landraces of hulless barley grown in variable environments has been seen to be an important task for designing targeted collections and introductions of germplasms (Muhe and Assefa 2011). Moreover, the nature of genetic variation will provide information of variability in the cultivars and the significance between the cultivars which are accessible and utilized in breeding programs. It has been observed that there are several approaches to assay genetic diversity in which one of them is the use of linear relationship between variables, conferring correlation analysis which is an useful tool for indirect selection of complex characters such as yield and quality traits ( Setotaw et al. 2014; Kaur et al. 2016). The coefficient of correlation shows 
the variations of common traits interactions under the study and does not imply causation (Mohtashami 2015).

However, in China even in diverse climatic and frequent drought conditions barley crop offers better alternative to extreme climates whether warm and winter seasons. Thus, when resources are limited and consumable cost and work time is laborious, the choice for estimation of genetic variation in hulless barley genetic resource germplasms are required for seed proteins and production. The analysis of different qualitative characters determined will identify variable hulless barley possessing low to high cultivars. This present study emphasizes the genetic diversity of hulless barley among various traits using different accessions of China from Tibet, Sichuan, Qinghai, and Gansu Provinces of China. The main objective of the study is to evaluate the genetic diversity in hulless barley, susing qualitative traits on the barley genotypes of China.

\section{Material and Methods}

\section{Plant materials}

The plant materials used in the current study comprised of 208 hulless barley genotypes including landrace, breeding lines, wild germplasm, and improved cultivars were collected from Tibet, Sichuan, Qinghai, and Gansu Provinces of China having wide variation for various qualitative traits.

\section{Experiment design and planting method}

The experiment was carried out at Chongzhou zone, Chengdu city of Sichuan province $\left(103^{\circ} 88^{\prime} \mathrm{E}\right.$, $30^{\circ} 82^{\prime} \mathrm{N}$; $548 \mathrm{~m}$ above sea level) of China during the 2016-2017 year. A field experiment was performed in a randomized complete block design with two replicates. Each plot of the field experiment had five rows with $1.5 \mathrm{~m}$ row long and spaced $0.35 \mathrm{~m}$ apart.

\section{Quality traits measure}

After harvest, NIRS DS 2500 (FOSS, Denmark) was used to measure the barley grain feed quality traits including crude protein, fiber, starch, neutral detergent fiber (NDF), acid detergent fiber (ADF).

\section{Data analysis}

The analysis of variance for mean comparisons and histogram was derived through Statistix v. 8.1 software. Correlation analysis was also conducted between crude protein, fiber, starch, neutral detergent fiber, and acid detergent fiber parameters by using the same software. The Euclidean distance within the accessions was quantified by NTSYS 2.1 software. Cluster analysis was also done through multivariate analysis by using the UPGMA method implied in MEGAX software. Clustering analysis helps in grouping the materials in such a manner that similar types were grouped together, while dissimilar ones belong to different groups.

\section{Results}

\section{Qualitative trait performance of Chinese hulless barley accessions}

Among 208 accessions of hulless barley, 111 cultivars were collected from the Tibet plateau, while others were related to different Chinese species. These accessions were used to determine the genetic diversity in some qualitative traits as crude protein, fiber, starch content, neutral detergent fiber, and acid detergent fiber.

The results of the analysis of variance for qualitative traits in barley accessions depicted that all were significantly different with high variability $(p \leq 0.0001$ ) (Table 1$)$. It means high genetic diversity was observed in these cultivars related to qualitative traits. 
Table 1. Analysis of variance (ANOVA) for various qualitative traits of 208 Chinese hulless barley accessions.

\begin{tabular}{cccc}
\hline Qualitative trait & Source of Variation & Df & MS \\
\hline \multirow{3}{*}{ Crude Protein } & Replication & 1 & 0.8420 \\
& Elite cultivars & 207 & $3.2237^{* * *}$ \\
& Error & 207 & 0.2218 \\
\hline \multirow{2}{*}{ Fiber } & Replication & 1 & 0.8741 \\
& Elite cultivars & 207 & $12.5774^{* * *}$ \\
& Error & 207 & 0.2136 \\
\hline \multirow{3}{*}{ Starch Content } & Replication & 1 & 5.4396 \\
& Elite cultivars & 207 & $46.3202^{* * *}$ \\
& Error & 207 & 2.7080 \\
\hline \multirow{3}{*}{ Neutral Detergent } & Replication & 1 & 0.0028 \\
& Elite cultivars & 207 & $21.6728^{* * *}$ \\
& Error & 207 & 0.3901 \\
\hline \multirow{3}{*}{ Acid detergent fiber } & Replication & 1 & 0.2229 \\
& Elite cultivars & 207 & $687.700^{* * *}$ \\
& Error & 207 & 18.6851 \\
\hline
\end{tabular}

***Highly significant at the probability level of 0.0001 .

\section{Coefficient of variation of qualitative traits of barley accessions}

Similarly, high genetic variability was observed between all the five qualitative traits. Crude protein in the dehulled covered barley grain varied from $8.49 \%$ to $9.37 \%$ (Table 2). The difference in crude protein concentration between these grain fractions was significant $(p<0.001)$. Moreover, the mean performance and coefficient of variation are depicted as $8.67 \%$ and $13.82 \%$, respectively. The trait crude protein showed maximum diversity among the genotypes. The fiber was recorded to have a range of $7.49 \%$ to $8.31 \%$. However, the coefficient of variation as $12.17 \%$ was recorded for crude protein showing diversity among the genotypes. Starch content was observed to have a variation ranged from $21.61 \%$ to $24.01 \%$. The highest mean value was found at $23.64 \%$ with a coefficient of variation as $12.87 \%$ for starch content exhibiting great diversity among the accessions. Subsequently, neutral detergent revealed to have a high mean value and coefficient of variation of $11.54 \%$ and $11.42 \%$, also contributing mean values ranging from $10.26 \%$ to $11.26 \%$ showing high diversity. Acid detergent fiber ranged from $4.11 \%$ to $4.52 \%$. Its mean value and coefficient of variation were observed to be less than $4.40 \%$ and $9.92 \%$. Hence, great diversity was observed among the barley accessions (Table 2).

Table 2. Mean values and coefficient of variation of qualitative traits of hulless barley accessions.

\begin{tabular}{cccccc}
\hline Categories & Crude protein & Fiber & Starch & Neutral detergent fiber & Acid detergent fiber \\
\hline Mean (\%) & 8.67 & 8.57 & 23.64 & 11.54 & 4.40 \\
Minimum (\%) & 8.49 & 7.49 & 21.61 & 10.26 & 4.11 \\
Maximum (\%) & 9.37 & 8.31 & 24.01 & 11.26 & 4.52 \\
SD & 1.19 & 1.04 & 2.78 & 1.31 & 0.43 \\
CV & 13.82 & 12.17 & 12.87 & 11.42 & 9.92 \\
\hline
\end{tabular}

SD - Standard Deviation; CV - Coefficient of Variation.

\section{Correlation coefficient determination for hulless barley accessions}

The correlation coefficient (Table 3 ) determined between crude protein in dehulled accession was positively highly significant $(p<0.01)$ with fiber $\left(r=0.33^{* * *}\right)$, acid detergent fiber $(r=0.29 * * *)$ and neutral detergent fiber $\left(r=0.32^{* * *}\right)$. This indicates the potential to produce well feed barley products using hulless barley grain characterized by high protein concentration. Fiber showed also highly significant association with acid detergent fiber $\left(r=0.83^{* * *}\right)$ and neutral detergent fiber $\left(r=0.96^{* * *}\right)$. While crude protein was found to have a negative correlation with starch as $r=-0.38^{* * *}$. Similarly, Starch content depicted a highly negative association with acid detergent fiber $\left(r=-0.83^{* * *}\right)$ and neutral detergent fiber $(r=-0.92 * * *)$. 
Table 3. Correlation coefficient for various qualitative traits of 208 hulless barley accessions.

\begin{tabular}{ccccc}
\hline Qualitative traits & Crude protein & Fiber & Starch content & Acid detergent fiber \\
\hline Fiber & $0.33^{* * *}$ & - & & \\
Starch content & $-0.38^{* * *}$ & $-0.92^{* * *}$ & - & \\
Acid detergent fiber & $0.29 * *$ & $0.83^{* * *}$ & $-0.76^{* * *}$ & - \\
Neutral detergent fiber & $0.32^{* * *}$ & $0.96^{* * *}$ & $-0.92^{* * *}$ & $0.93^{* * *}$ \\
\hline
\end{tabular}

Statistical analysis (t-Test) was performed for qualitative traits of hulless barley to compare the different districts among 208 hulless barley accession. Statistically significant difference was measured by $(P<0.01)$ pool value among all the qualitative traits.

Selected areas for the trait crude protein had highly association with Sichuan, with Qinghai as well as a positive association of Tibet and Yunnan with Qinghai district. Among all the selected locations for the character fiber in various hulless barley genotypes. Tibet had positively correlated with Canada, Gansu, and Qinghai and Canada with Gansu. While Sichuan correlated with Gansu and Yunnan. Gansu is positively correlated with Yunnan, but Yunnan had a negative but positive association with Qinghai. Moreover, the trait neutral detergent fiber had a positive association with Sichuan and Qinghai as well as Canada also performed the same with Gansu and Yunnan. As Sichuan performed well in all for many traits hence also for neutral detergent fiber had positively correlated with Gansu and Yunnan. Gansu also had positively associated with Yunnan and Qinghai. Qinghai also remained positive for Yunnan. However, remained all the locations were non-significant. Hence Tibet significantly showed association with Canada, Gansu, and Qinghai. Whereas, Canada had a positive association with Sichuan, Gansu, and Yunnan. Sichuan also had a positive correlation between Gansu and Yunnan. In addition to significant association, Qinghai had proven to positive correlation for Gansu and Yunnan. For the trait ADF, two areas performed best with two areas, as Tibet had a positive association with Canada and Qinghai along with this Canada also remained significantly associated with Sichuan and Gansu (Table 4). 
Table 4. The comparisons of difference for qualitative traits among hulless barley accessions from different regions.

\begin{tabular}{|c|c|c|c|c|c|c|}
\hline \multicolumn{7}{|c|}{ Crude Protein } \\
\hline Areas & Tibet & Canada & Sichuan & Gansu & Yunnan & Qinghai \\
\hline Tibet & & $-0.19 n s$ & $-0.46 n s$ & $0.12 \mathrm{~ns}$ & $-0.44 n s$ & $0.52 *$ \\
\hline Canada & & & $-144.05 n s$ & $0.32 \mathrm{~ns}$ & $-0.24 n s$ & $0.72 \mathrm{~ns}$ \\
\hline Sichuan & & & & $0.58 \mathrm{~ns}$ & $0.02 \mathrm{~ns}$ & $0.98 * *$ \\
\hline Gansu & & & & & $-0.56 n s$ & $0.39 n s$ \\
\hline Yunnan & & & & & & $-0.96^{*}$ \\
\hline Qinghai & & & & & & \\
\hline
\end{tabular}

\begin{tabular}{|c|c|c|c|c|c|c|}
\hline \multicolumn{7}{|c|}{ Fiber } \\
\hline Areas & Tibet & Canada & Sichuan & Gansu & Yunnan & Qinghai \\
\hline Tibet & & $0.72 * *$ & $0.32 \mathrm{~ns}$ & $-2.23 *$ & $-0.58 n s$ & $0.59 *$ \\
\hline Canada & & & $-148.19 n s$ & $2.95^{*}$ & $-1.31 \mathrm{~ns}$ & $-0.13 n s$ \\
\hline Sichuan & & & & $2.55^{*}$ & $-0.90 * *$ & $0.27 \mathrm{~ns}$ \\
\hline Gansu & & & & & $1.64 * *$ & $2.77 \mathrm{~ns}$ \\
\hline Yunnan & & & & & & $-1.13^{*}$ \\
\hline \multicolumn{7}{|l|}{ Qinghai } \\
\hline \multicolumn{7}{|c|}{ Starch } \\
\hline Areas & Tibet & Canada & Sichuan & Gansu & Yunnan & Qinghai \\
\hline Tibet & & $0.25^{*}$ & $-1.49 n s$ & $2.62 *$ & $0.68 n s$ & $-2.09 * *$ \\
\hline Canada & & & $-109.07 *$ & $2.37^{* *}$ & $0.43^{*}$ & $-2.34 n s$ \\
\hline Sichuan & & & & $4.12 *$ & $2.18^{*}$ & $-0.59 n s$ \\
\hline Gansu & & & & & $-1.94 n s$ & $-4.72 *$ \\
\hline Yunnan & & & & & & $2.78^{*}$ \\
\hline \multicolumn{7}{|l|}{ Qinghai } \\
\hline \multicolumn{7}{|c|}{ Neutral detergent fiber } \\
\hline Areas & Tibet & Canada & Sichuan & Gansu & Yunnan & Qinghai \\
\hline Tibet & & $0.17 n s$ & $0.73^{*}$ & $-3.04 n s$ & $-0.37 n s$ & $0.83^{*}$ \\
\hline Canada & & & $-140.83 n s$ & $2.87^{* *}$ & $-0.19 * *$ & $1.00 \mathrm{~ns}$ \\
\hline Sichuan & & & & $3.77^{*}$ & $-1.09 * *$ & $0.10 \mathrm{~ns}$ \\
\hline Gansu & & & & & $2.68 * *$ & $3.90 *$ \\
\hline Yunnan & & & & & & $-1.23^{*}$ \\
\hline Qinghai & & & & & & \\
\hline \multicolumn{7}{|c|}{ Acid detergent fiber } \\
\hline Areas & Tibet & Canada & Sichuan & Gansu & Yunnan & Qinghai \\
\hline Tibet & & $0.36 * *$ & $0.30 n s$ & $-0.97 n s$ & $-0.21 n s$ & $0.16^{*}$ \\
\hline Canada & & & $-151.68 * *$ & $0.62 * *$ & $0.15 n s$ & $0.52 \mathrm{~ns}$ \\
\hline Sichuan & & & & $1.28 \mathrm{~ns}$ & $-0.52 n s$ & $-0.14 n s$ \\
\hline Gansu & & & & & $0.76 \mathrm{~ns}$ & $1.18 \mathrm{~ns}$ \\
\hline Yunnan & & & & & & $-0.42 n s$ \\
\hline Qinghai & & & & & & \\
\hline
\end{tabular}

${ }^{*}$ and ${ }^{* *}$ indicate significant difference at the probability levels of 0.05 and 0.01 , respectively; $n$ indicates no significant difference.

\section{Frequency distribution of different qualitative traits of hulless barley}

The measured (histogram) and fitted (line) frequency distributions studied in 208 different genotypes of hulless barley accessions with five different characters, Crude Protein, fiber, starch, neutral detergent fiber, and acid detergent fiber, in results normal distribution in the histogram in each character is explained (Figure 1). The form of the fitted distribution was minimum and maximum. The Crude Protein in hulless barley samples covered the complete range of the data obtained for the different types of 208 Chines hulless barley accessions that were from $6.2 \%$ to $13.0 \%$ and were normally distributed around $8.8 \%$. The data for 
fiber in hulless barley was normally distributed around the mean values of $5 \%$, respectively. In contrast, the hulless barley starch levels were normally distributed around $45 \%$, with the highest level of varieties were included among the 208 Chinese hulless barley. The data of neutral detergent fiber were normally distributed around $12 \%$. The acid detergent fiber obtained for the 208 Chinese hulless barley samples were normally distributed around $0.6 \%$ (Figure 1 ).

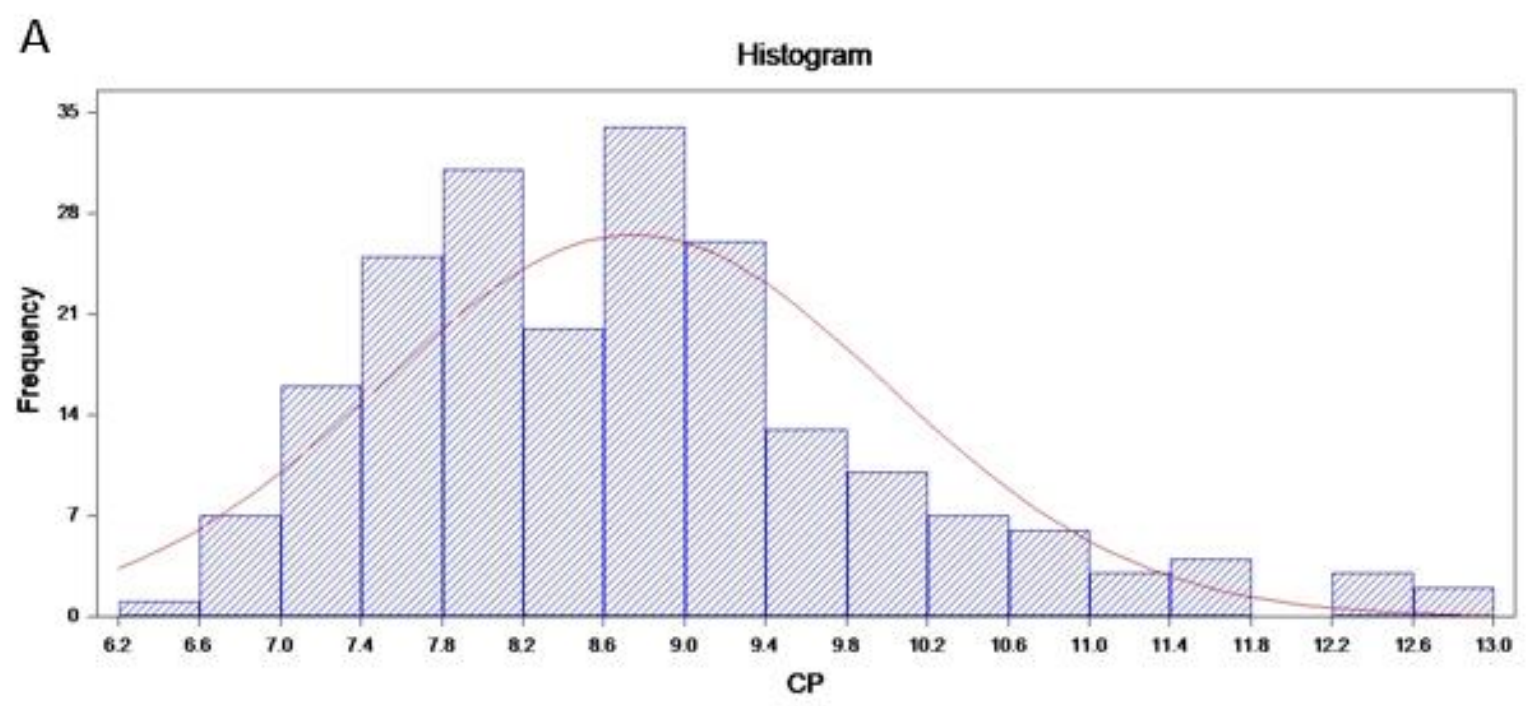

200 cares plofted 208 messing crass

B

Histogram

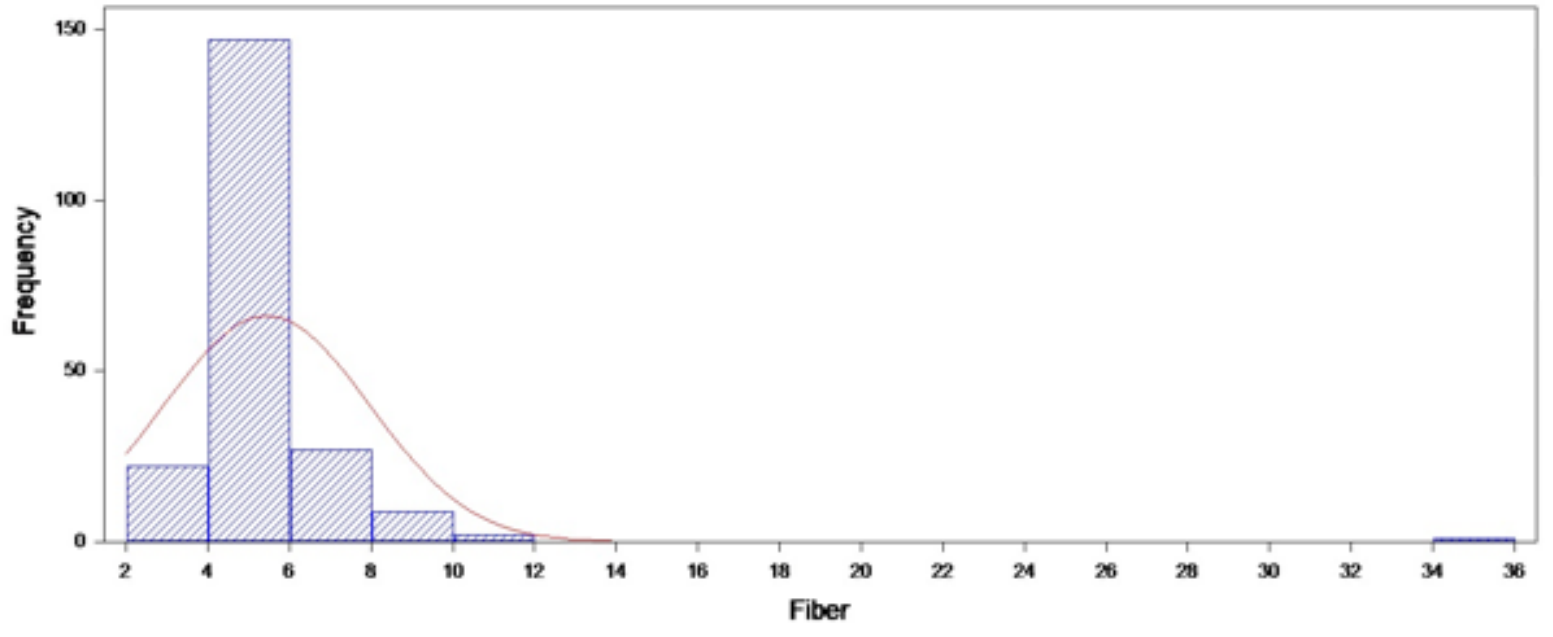

208 curses plotlod 208 mising curnes

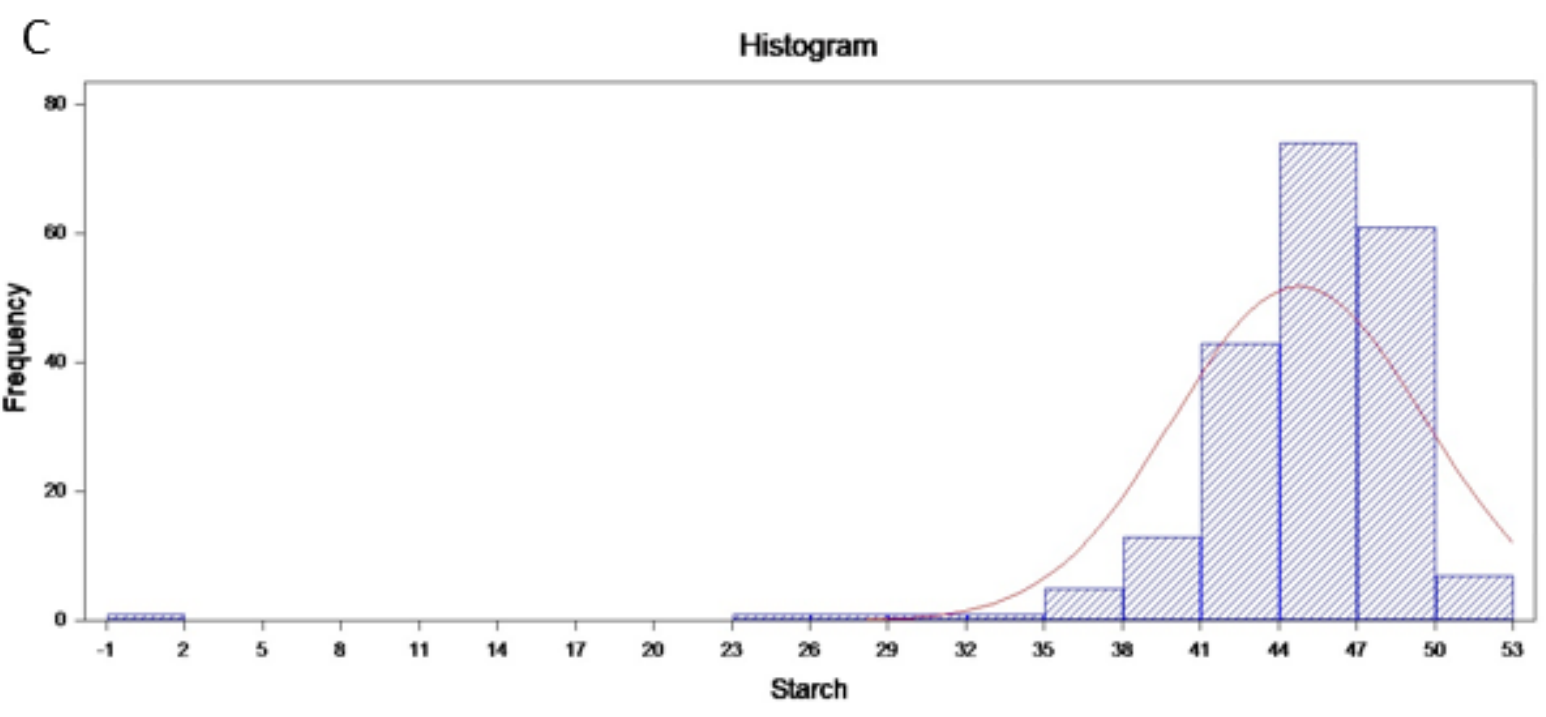

208 cases plottod 208 missing creses 


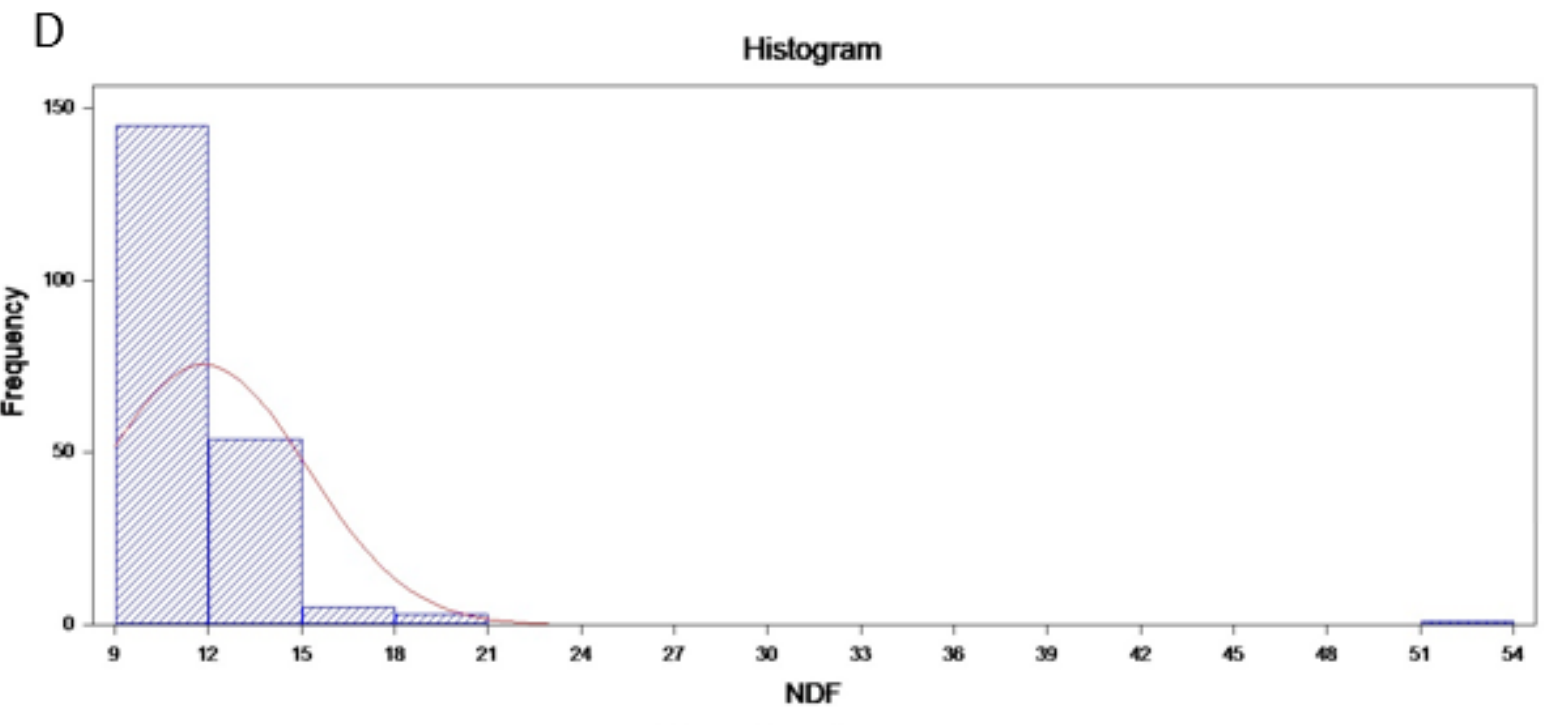

208 cuses photlod 208 missing cares

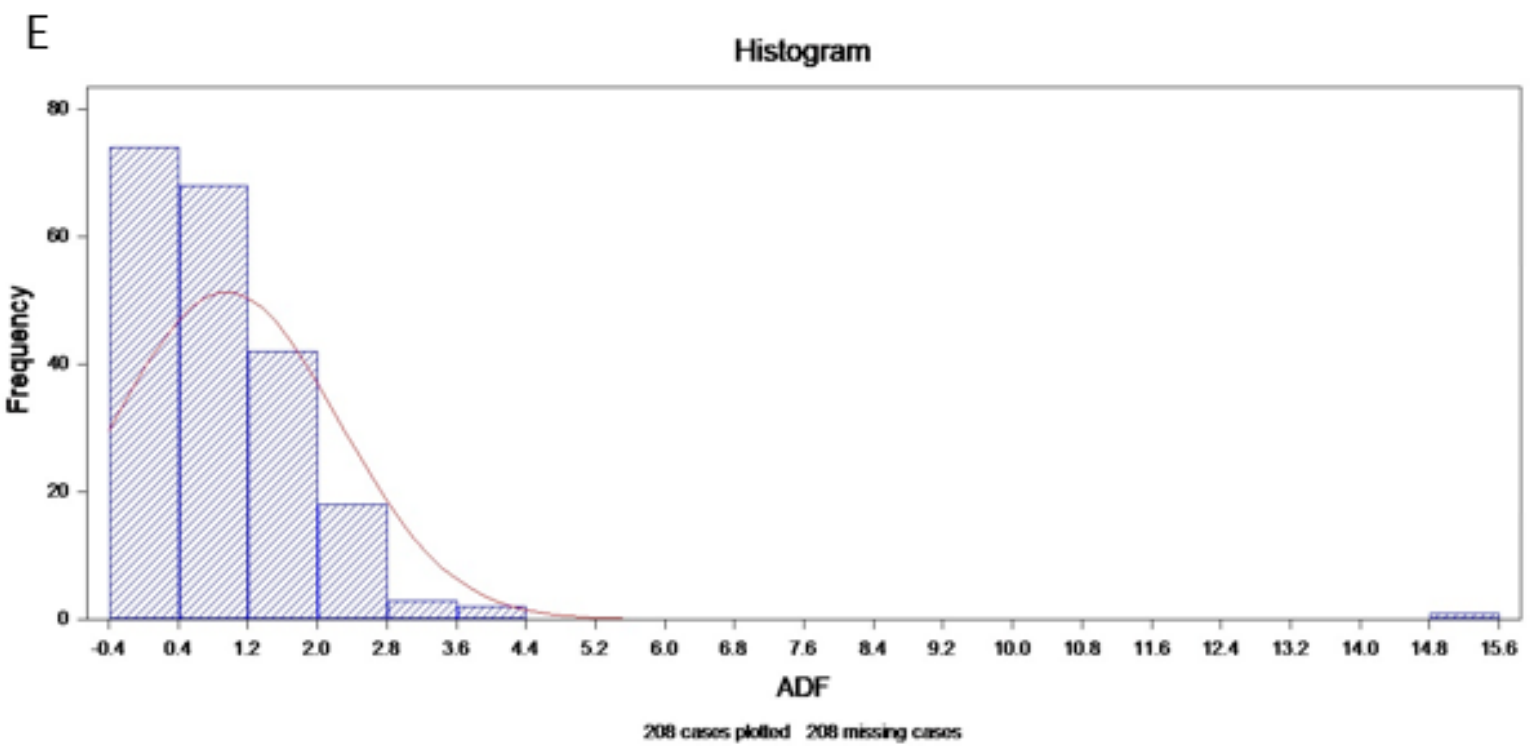

Figure 1. Histograms showing the frequency distribution of different qualitative traits of hulless barley. A histograms showing the frequency distribution of Crude Protein (CP) of hulless barley; $B$ - histograms showing the frequency distribution of Fiber of hulless barley; $\mathrm{C}$ - histograms showing the frequency distribution of Starch of hulless barley; D - histograms showing the frequency distribution of Neutral Detergent Fiber (NDF) of hulless barley; E - histograms showing the frequency distribution of Acid Detergent Fiber (ADF) of hulless barley.

\section{Phylogenetic relationships and evolutionary patterns of hulless barley accessions}

To investigate the phylogenetic relationships and evolutionary patterns among the 208 Chinese accessions, a phylogenetic tree was constructed. According to the topology structure of the tree, the clustering tree was divided into five groups (Group 1-5, Figure 2). Group 1 (represented blue color) consisted of Tibet, Gansu, Canada, Sichuan, and Qinghai, Yunnan districts accessions and is the largest group with a maximum of 105 accessions. A large variation was found in the same group. The second largest group (represented orange group) prevailed to have 33 accessions. Most of them existed in the third group (represented green color) consists of major 54 accessions. Furthermore, the group four (red color) is composed of twelve accessions group. Whereas the last fifth group (represented yellow color) contained only four accessions, including Tibet and Gansu districts. These results clearly revealed the geographical differentiation of Chinese hulless barley landraces in Tibet, Gansu, Qinghai, Sichuan, USA, and Canada. 


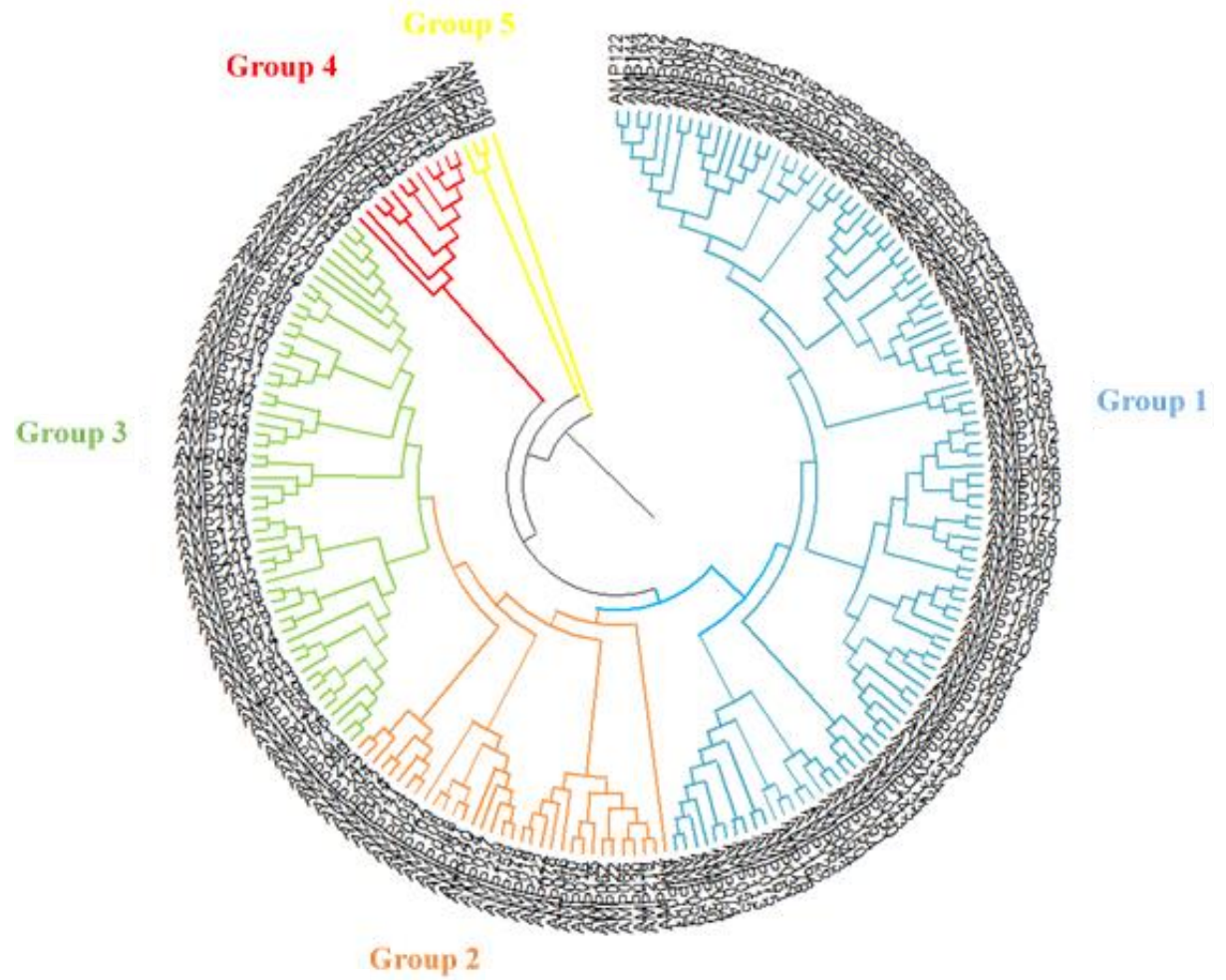

Figure 2. Phylogenetic tree of hulless barley accessions of a total of 208 accessions of hulless barley; 116 cultivars from Tibet plateau and remaining Chinese species were analyzed by using neighbor-joining tree which was constructed by applying MEGA X software.

\section{Discussion}

Presently, this genetic study on complex qualitative traits in barley crop have been found rarely in research areas; Previous reports on qualitative studies have demonstrated only in a smaller number of barley accessions, to identify potential signals of adaptation and domestication. Amongst all selected areas, the trait crude protein had highly association of Sichuan with Qinghai as well as a positive association of Tibet and Yunnan with Qinghai district. Additionally, Tibet had positive relationship with Canada, Gansu, and Qinghai and Canada with Gansu. While, Sichuan had also a correlation with Gansu and Yunnan. Gansu is positively correlated with Yunnan, but Yunnan had a negative but positive association with Qinghai. Moreover, the trait of neutral detergent fiber had a positive association with Sichuan and Qinghai as well as Canada also performed the same with Gansu and Yunnan. All over the provinces, Sichuan performed well for most of the traits. For neutral detergent fiber also showed positive correlation with Gansu and Yunnan. Gansu also had positively associated with Yunnan and Qinghai. Hence Tibet significantly showed association with Canada, Gansu, and Qinghai. Whereas, Canada had a positive association with Sichuan, Gansu, and Yunnan. Sichuan also had a positive correlation between Gansu and Yunnan. In addition to significant association, Qinghai had proven to positive correlation for Gansu and Yunnan. In order to figure out the sustained productivity, the evaluation and identification of potentially useful germplasm is the first and foremost step in a crop improvement program. Though, to sustain the high productivity level of barley, genetic variability existing in nature or created through crop breeding is of immense value. Genetic uniformity within a crop is readily brought by using the same gene or gene of a complex during breeding programs. When uniformity becomes the cause of genetic vulnerability, then genetic diversity is the only insurance against it (Sanghera et al. 2014). In the present work, the diversity was observed in different barley accessions from different Provinces. The analysis of variance revealed that all the varieties performed significantly $(P \leq 0.01)$ as the high genetic variability was observed between all the five qualitative traits including crude protein, fiber, starch, neutral detergent fiber, and acid detergent fiber. It is suggested that studied materials possess rich genetic diversity resources for a variety of traits thus can extensively be used for upcoming breeding programs. Almost similar results have also been reported by (Kaur et al. 2016). Determining the phenotypic variation of crude protein, fiber, starch, neutral detergent fiber and acid detergent fiber in a segregating population is a prerequisite for elucidating its genetic foundation and for 
breeding barley cultivars. Extensive variation in grain protein content (GPC) in different barley genotypes has been reported previously. For instance, QTL analysis provides an efficient way to look for associations between the phenotypic variance has been widely used in dissecting GPC variation in barley populations. However, the lack of parental lines with high GPC in most previous studies may have hindered the detection of possible major QTLs for GPC (Fan et al. 2017). In the current study, Crude protein in the dehulled covered barley grain varied from $8.49 \%$ to $9.37 \%$ (Table 2 ). The difference in crude protein concentration between these grain fractions was significant $(p<0.001)$. Moreover, the mean performance and coefficient of variation are depicted as $8.67 \%$ and $13.82 \%$, respectively. The trait crude protein showed maximum diversity among the genotypes.(Bleidere et al. 2017). The data for the Fiber trait was recorded to have a range of $7.49 \%$ to $8.31 \%$. However, the coefficient of variation as $12.17 \%$ was recorded for crude protein showing diversity among the genotypes. Starch content was observed to have a variation ranged from $21.61 \%$ to $24.01 \%$. The highest mean value was found as $23.64 \%$ with a coefficient of variation as $12.87 \%$ for starch content exhibiting great diversity among the accessions. Subsequently, neutral detergent revealed to have a high mean value and coefficient of variation of $11.54 \%$ and $11.42 \%$, also contributing mean values ranging from $10.26 \%$ to $11.26 \%$ showing high diversity. Acid detergent fiber ranged from $4.11 \%$ to $4.52 \%$. Its mean value and coefficient of variation was observed to be less as $4.40 \%$ and $9.92 \%$. Hence, a great diversity was observed among the barley accessions. (Dyulgerova et al. 2017). The correlation coefficient is statistically an important technique which can assist barley breeder in the selection of crop plants for higher yield. The correlation coefficient determined between the crude protein in dehulled accession was positively highly significant ( $p<0.01$ ) with fiber, acid detergent fiber, and neutral detergent fiber (Bleidere and Gaile 2012). Similarly, the correlation of coefficients was highly significant but negatively correlated with the crude protein, acid detergent fiber and neutral detergent fiber were reported by (Jancik et al. 2008). The results indicated the potential to produce well feed barley product using hulless barley grain with high protein concentration (Cardinal et al. 2003). Crude protein was found to have a negative correlation with starch content as the same result compared with (Kaur et al. 2016; Bleidere et al. 2017; Dyulgerova et al. 2017). Similarly, starch showed a highly negative significance associated with acid detergent fiber and neutral detergent fiber, almost similar results have also been reported by Mut et al. (2016). The measurement of (histogram) and fitted (line) frequency distributions were studied in 208 various genotypes of hulless barley crop with five different characters like crude protein, fiber, starch, neutral detergent fiber, and acid detergent fiber, all histogram showed normal distribution in each trait (Cai et al. 2013; Elakhdar et al. 2018). Cluster tree of hulless barley accessions is one of the most important statistical analysis, which helps to divide in the grouping of genotypes in different groups based on genetic variability which existing for various traits. further, the cluster tree was divided into five groups consisting of Tibet, Gan Su, Canada, USA, Sichuan, and Qinghai district accessions that existed large genetic variation within and among the accessions. In Group 1, (105) accessions widely from the region of Tibet (49), Gansu (7), Canada (1), Sichuan (16) and Qinghai (29), Yunnan (3) were considered in this study. This clearly demonstrates that high variation was observed between the 87 accessions. This indicates the presence of wide genetic variation among the tested genotypes. Amongst all 208 accessions distance coefficient ranging between 0.28 and 75.86 . In the present study, the diversity level was as high as shown in previous studies (Wang et al. 2015; Zang et al. 2015; Guo et al. 2018).

\section{Conclusions}

In this study, we identified the genetic diversity of newly evolved 208 genotypes of hulless barley. We found that a very large genetic diversity was observed through cluster analysis among all the 208 barley accessions with a distance coefficient ranging between 0.28 and 75.86 . Consequently, the structured study initiated that from the categorized groups, the best performance and significant response of different traits such as crude protein, fiber, starch, neutral detergent fiber, and acid detergent fiber were observed in group 1, (105) accessions widely from the region of Tibet (49), Gansu (7), Canada (1), Sichuan (16) and Qinghai (29), Yunnan (3). In addition, the histogram revealed that frequency distributions of 208 different genotypes of hulless barley crop showed normal distribution. Our results confirm that the hulless barley used in this study has a high degree of genetic diversity and shows great promise for identifying the genetic diversity of adaptive traits. Therefore, the findings presented here could help us deepen our understanding of the 
genetic mechanisms of adaptive traits and carry out marker-assisted selection for important traits in the breeding of hulless barley.

Authors' Contributions: MEMON, S.: acquisition of data, analysis and interpretation of data, drafting the article; YANG, S.: conception and design, and acquisition of data; LIU, X. and HE, X.: conception and design, acquisition of data, analysis and interpretation of data, drafting the article, and critical review of important intellectual content; MEMON, S., KHASKHELI, M.I. and FENG, Z.: .: conception and design, acquisition of data, analysis and interpretation of data, drafting the article, and critical review of important intellectual content. All authors have read and approved the final version of the manuscript.

Conflicts of Interest: The authors declare no conflicts of interest.

Ethics Approval: Not applicable.

Acknowledgments: The authors would like to thank the funding for the realization of this study provided by the National Key Research \& Development Program of China, Finance Code 2018YFD1000705, International Science and Technology Cooperation in Sichuan Provice of China, Finance Code 2021YFH0113, and China Agriculture Resarch System, Finance Code CARS-05.

\section{References}

BAIK, B.K., 2014. Processing of barley grain for food and feed barley. IN: SHEWRY, P.R. and Ullrich, S.E. (Eds). Barley: Chemistry and Technology. $2^{\text {nd }}$ Ed. Amsterdam: Elsevier, p. 233-268. https://doi.org/10.1016/B978-1-891127-79-3.50010-X

BLEIDERE, M. and GAILE, Z. Grain quality traits important in feed barley. Proceedings of the Latvian Academy of Sciences. Section B. Natural, Exact, and Applied Sciences. 2012, 66(1),1-9. https://doi.org/10.2478/v10046-011-0039-8

BLEIDERE, M., et al. Biochemical Composition of Spring Barley Grain Pearled to Varying Degrees. Proceedings of the Latvian Academy of Sciences. Section B. Natural, Exact, and Applied Sciences. 2017, 71(6), 468-473. https://doi.org/10.1515/prolas-2017-0082

CAI, S., et al. Grain protein content variation and its association analysis in barley. BMC plant biology. 2013, 13, 35. https://doi.org/10.1186/1471-2229-13-35

CARDINAL, A., LEE, M. and MOORE, K. Genetic mapping and analysis of quantitative trait loci affecting fiber and lignin content in maize. Theoretical and Applied Genetics. 2003, 106, 866-874. https://doi.org/10.1007/s00122-002-1136-5

DYULGEROVA, B., DYULGEROV, N. and DIMOVA, D. Variation in the chemical composition and physical characteristics of grain from winter barley varieties. Agricultural Science and Technology. 2017, 9(9), 198-202. https://doi.org/10.15547/ast.2017.03.036

ELAKHDAR, A., et al. Assessment of genetic diversity in Egyptian barley (Hordeum vulgare L.) genotypes using SSR and SNP markers. Genetic resources crop evolution. 2018, 65, 1937-1951. https://doi.org/10.1007/s10722-018-0666-x

ESHGHI, R. and AKHUNDOVA, E. Genetic diversity in hulless barley based on agromorphological traits and RAPD markers and comparison with storage protein analysis. African Journal of Agricultural Research. 2010, 5(1), 97-107. https://doi.org/10.5897/AJAR09.363

FAN, C., et al. Identification of QTLs controlling grain protein concentration using a high-density SNP and SSR linkage map in barley (Hordeum vulgare L.). BMC plant biology. 2017, 17, 122. https://doi.org/10.1186/s12870-017-1067-6

FERREIRA, J.R., et al. Assessment of genetic diversity in Brazilian barley using SSR markers. Genetics and molecular biology. 2016, 39(1), 86-96. http://dx.doi.org/10.1590/1678-4685-GMB-2015-0148

GOUS, P.W., GILBERT, R.G. and FOX, G.P. Drought-proofing barley (Hordeum vulgare) and its impact on grain quality: A review. Journal of the Institute of Brewing. 2015, 121, 19-27. https://doi.org/10.1002/jib.187

GUO, J., et al. Identification and Expression Analysis of Wheat TaGF14 Genes. Frontiers in genetics. 2018, 9, 12.

https://doi.org/10.3389/fgene.2018.00012

GUO, Y., et al. Genetic diversity analysis of hulless barley from Shangri-la region revealed by SSR and AFLP markers. Genetic resources and crop evolution. 2012, 59(7) 1543-1552. https://doi.org/10.1007/s10722-011-9783-5

JANCIK, F., et al. Determination of indigestible neutral detergent fibre contents of grasses and its prediction from chemical composition. Czech Journal of Animal Science-UZPI. 2008, 53(3),128-135. https://doi.org/10.17221/2716-CJAS

KAUR, S., et al. Genetic variation and evaluation of exotic barley (Hordeum vulgare L.) genotypes for grain protein content, starch content and agronomic traits. Electronic Journal of Plant Breeding. 2016, 7(4), 1114-1121. https://doi.org/10.5958/0975-928X.2016.00154.X

KUMAR, D., et al. Scope of food barley research annd development in India. Wheat and Barley Research. 2018, 10(8), 166-172. https://doi.org/10.25174/2249-4065/2018/84878

KUMAR, V., et al. Barley research in India: Retrospect \& prospects. Journal of Wheat Research. 2014, 6(1),1-20.

LIU, B., et al. Determining factors for the diversity of hulless barley agroecosystem in the himalaya region-A case study from Northwest Yunnan, China. Global Ecology and Conservation. 2019, 18, e00600. https://doi.org/10.1016/j.gecco.2019.e00600 
MATSUMOTO, T., et al. Comprehensive sequence analysis of 24,783 barley full-length cDNAs derived from 12 clone libraries. Plant physiology. 2011, (156), 20-28. https://doi.org/10.1104/pp.110.171579

MOHTASHAMI, R. The correlation study of important barley agronomic traits and grain yield by path analysis. Biological Forum. 2015, 7(1),1211-1219.

MUHE, K. and ASSEFA, A. Diversity and agronomic potential of barley (Hordeum vulgare L.) landraces in variable production system, Ethiopia. World Journal of Agricultural Sciences. 2011, 7(5),599-603.

MUT, Z., KOSE, O. and AKAY, H. Grain yield and some quality traits of different oat avena sativa L. genotypes. Journal of Agronomy and Agricultural Aspects. 2016, 2(12), 83-88.

NARWAL, S., et al. Hulless barley as a promising source to improve the nutritional quality of wheat products. Journal of food science and technology. 2017, 54, 2638-2644. http://dx.doi.org/10.1007/s13197-017-2669-6

SANGHERA, G., et al. Agro-morphological and genetic diversity among elite wheat genotypes grown under Kashmir conditions. International Journal of Current Research. 2014, 8(6),7735-7740.

SETOTAW, T., et al. Developing selection criteria based on an ontogenetic path analysis approach to improve grain yield in barley. Genetics and Molecular Research. 2014, 13(2), 4635-4646. http://dx.doi.org/10.4238/2014.June.18.6

WANG, Y., et al. Origin of worldwide cultivated barley revealed by NAM-1 gene and grain protein content. Frontiers in plant science. 2015, 6, 803. https://doi.org/10.3389/fpls.2015.00803

YOUSSEF, M., et al. Nutritional assessment of barley, talbina and their germinated products. Scientific Journal of Crop Science. 2013, 3(2),5665.

ZANG L., et al. Genome-wide analysis of the fasciclin-like arabinogalactan protein gene family reveals differential expression patterns, localization, and salt stress response in Populus. Frontiers in plant science. 2015, (6), 1140. https://doi.org/10.3389/fpls.2015.01140

ZENG, X., et al. The draft genome of Tibetan hulless barley reveals adaptive patterns to the high stressful Tibetan Plateau. Proceedings of the National Academy of Sciences. 2015, 112(4), 1095-1100. https://doi.org/10.1073/pnas.1423628112

ZHU, F. Barley starch: Composition, structure, properties, and modifications. Comprehensive Reviews in Food Science and Food Safety. 2017, 16, 558-579. https://doi.org/10.1111/1541-4337.12265

Received: 10April 2020 | Accepted: 14 December 2020 | Published: 20 August 2021

This is an Open Access article distributed under the terms of the Creative Commons Attribution License, which permits unrestricted use, distribution, and reproduction in any medium, provided the original work is properly cited. 